Chen, J. C., \& Dobinson, T., \& Kent, S. (2019). Lecturers' perceptions and experiences of Blackboard Collaborate as a distance learning and teaching tool via Open Universities Australia (OUA). Open Learning: The Journal of Open, Distance and e-Learning. Advanced online publication. https://doi.org/10.1080/02680513.2019.1688654 


\section{Lecturers' Perceptions and Experiences of Blackboard Collaborate as a Distance Learning and Teaching Tool via Open Universities Australia (OUA)}

\section{Introduction}

Online learning has grown rapidly in the last decade. Constantly evolving web-based technology enables universities to deliver course content in more flexible ways for an increasingly diverse student population (Keengwe \& Kidd, 2010). As such, courses are offered either wholly online for off-campus students or in a blended format where students attend classes on campus and engage in online learning activities (Reese, 2014). One of the largest providers of online higher education in Australia is Open Universities Australia (OUA) which offers students enrolment in online coursework delivered by partner institutions (King, 2010). OUA students graduate with an identical qualification to their oncampus counterparts but with the benefit of flexible study (OUA, 2019). For these distance learners, whose only interaction with lecturers and classmates is via the Internet, the mode of online course delivery plays an important role in student learning and engagement.

Online courses are generally offered through: asynchronous, synchronous and blended (hybrid) delivery modes (Allen \& Seaman, 2010). The asynchronous mode is where all the lecture materials and tutorials are available offline and students engage with lecturers and peers via discussion forums at a time of their choosing. The synchronous mode is where lecturers and students can interact in real time via web conferencing using electronic learning management systems (LMS), such as Blackboard. Blended learning, the third mode, is a combination of online and face-to-face settings (Ekwunife-Orakwue \& Teng, 2014). Blackboard Collaborate, one of the LMS features embedded in Blackboard, allows lecturers to conduct virtual classroom sessions in real time. This synchronous platform enables twoway audio and video conferencing as well as PowerPoint presentations using interactive 
whiteboard and screen sharing (Nelson, 2017). Students are able to collaborate with peers and interact with the teacher in the same virtual space, at the same time, as if attending a face-toface class on campus (Francescucci \& Rohani, 2019). As long ago as 2002, Schroeder talked about the advantages of using synchronous online learning to enhance the learning experience and foster co-presence (the sense of being there together) by mitigating the virtual distance (Schroeder, 2002). To date most studies on the use of Blackboard Collaborate for online learning have been conducted outside of Australia (cf. Lavine, Greenburg, Chen, Kao, \& Lin, 2012; Tonsmann, 2014). This project, therefore, aims to investigate 1) the usefulness of Blackboard Collaborate for unit lecturers and coordinators who conduct their units online, 2) the challenges presented by Blackboard Collaborate for the teaching staff in one particular Australian university setting, and 3) the impact of Blackboard Collaborate on distance learning and teaching via OUA.

\section{Literature Review}

\section{Online Delivery Modes}

Online content can be delivered in asynchronous mode primarily through LMS (e.g., Blackboard or Moodle) where lecturers upload course materials for students to access at any time (Alexander, Lynch, Rabinovich, \& Knutel, 2014). LMS tools such as blogs, wikis and discussion boards are used to facilitate student interaction and community (Alexander et al., 2014). A distinct advantage of this delivery mode is that it offers flexibility of time which is one of the reasons students enroll in online education in the first instance (Hrastinksi, 2008). However, disadvantages of this delivery mode include feelings of detachment or isolation for students (Huang \& Hsiao, 2012) and delayed instructor feedback or peer-engagement (Alexander et al., 2014). Additionally, online units offered asynchronously often provide online students with recordings of lectures delivered to on-campus students with whom they have no opportunity to 'collaborate or co-construct' meaning (Irvine, Code \& Richards, 2013, 
p. 177). For the lecturers, responding to individual student discussion board posts asynchronously can be very time-consuming (Huang \& Hsiao, 2012).

An alternative for online education is synchronous mode which can be used for student/teacher interaction in real time via live video streaming (Rudd \& Rudd, 2014; Yamagata-Lynch 2014). Recent technological advancements allow a richer degree of synchronous interaction (Martin, Parker, \& Deale, 2012) that resembles on-campus classrooms (Francescucci \& Rohani, 2019; Tunceren, Kaur, Mullins, \& Slimp, 2015) by capitalising on web-conferencing features, such as 'audio conferencing, videoconferencing, real-time polling and quizzes, application sharing, text chat, playing of audio and video files, file transfer, whiteboard, shared web browsing, break-out rooms for small group discussion and recording functions' (Cornelius, 2014, p. 260). Advantages of this mode include reduced isolation for online students, social presence and communities of learning (Akarasriworn \& Ku, 2013; Peacock et al., 2012; Hrastinski, 2008), immediate tutor feedback (Martin et al., 2012) and tutor's non-verbal communication signals via video feed (Rudd \& Rudd, 2014). Connections with peers and lecturers can also be strengthened due to the spontaneity of live discussion compared to the asynchronous mode (Yamagata-Lynch, 2014; Huang \& Hsiao, 2012) where students tend to post their own views on an issue but may not interact with the opinions of others (Martin, Parker \& Deale, 2012). Reported drawbacks of this delivery mode include the lack of flexibility of time (Huang \& Hsiao, 2012) and technical issues during live delivery such as low quality audio or video which detract from learning activities for both students and lecturers (Akarasriworn \& Ku, 2013; Peacock et al., 2012; Michael, 2012). A further challenge surrounding synchronous mode is that student interactions can be a challenge to manage online. Cornelius (2014) describes problems that lecturers may encounter ensuring all students are able to voice their opinions, dealing with individuals who 
interrupt or dominate the discussions, as well as being prepared to restart discussions that have diminished.

\section{Lecturers' Experiences of Using Virtual Classroom Software}

Of interest to this particular study is Blackboard Collaborate $(\mathrm{BC})$, the synchronous virtual classroom software within the Blackboard LMS. BC was developed in 2010 when Blackboard Inc. acquired two other popular synchronous learning platforms: Elluminate Inc. and Wimba Inc. They combined expertise in these previous forms to develop the BC platform ("Blackboard to Acquire Elluminate," 2010). BC offers numerous features to increase student interaction and participation including two-way voice facilities and video camera feed for up to five cameras, instant classroom chat, an editable, interactive whiteboard, application sharing, file sharing and participation features such as hand raising (Blackboard, 2019). Studies on the use of BC for fully online students in the Australian context are scarce unlike those conducted on its predecessors. Elluminate and Wimba are equivalent synchronous platforms and thus have relevance for tutor perspectives on the usefulness of synchronous software historically.

Studies conducted into lecturers' views of Elluminate and Wimba Classroom have revealed similar findings to those of BC. First of all, synchronous virtual classrooms afford lecturers the flexibility of working from home and the ability to teach whilst travelling (Michael, 2012). Another benefit for lecturers is being able to connect with students from around the world (Kear, Chetwynd, Williams \& Donelan, 2012; Lonie \& Andrews, 2009; Lonie, 2012; Reushle \& Loch, 2008). Provision of feedback is made instantaneous with Elluminate (Carrington, Kim \& Strooper, 2010) and more efficient as it eliminates the need to answer the same online student query multiple times (Reushle \& Loch, 2008). Although lecturers raise concerns about the limited use of body language and facial expressions in both Elluminate and Wimba studies (Kear et al., 2012), this lack of non-verbal cues as a means of 
gaining student feedback requires lecturers to be more deliberate in checking understanding (Lonie \& Andrews, 2009). However, tutors have emphasised the need for training and practice with these tools and lesson preparation has also been reported to be more time consuming, often requiring lecturers to establish a new repository of learning materials as face-to-face resources are not easily transferrable in content (Kear et al., 2012) or convertible in form (Lonie \& Andrews, 2009).

Studies have also shown that lecturers find it difficult to encourage students to attend live sessions throughout the semester (Reushle \& Loch, 2008; Rogers, 2011). Use of audio and video feed were found to be important in creating a social connection between lecturers and students but similar to the findings of BC studies, lecturers found that some students can be reluctant to use their camera and microphone (Kear et al., 2012) and may be passive in their participation; listening but not actively engaging (Rogers, 2011). Lastly, the technical difficulties inherent in all of these modes have been reported by lecturers as being frustrating and demanding (Lavine et al., 2012).

\section{Lecturers' Views about BC as a Distance Learning and Teaching Tool}

Several themes emerge in the literature about lecturers' experiences with BC. Firstly, careful planning and preparation is required on the part of the lecturer to deliver quality learning experiences in a synchronous online classroom (Yamagata-Lynch, 2014) and this may require more planning than asynchronous or face-to-face teaching (Bower, Kenney, Dalgarno, Lee, \& Kennedy., 2014). Next, it is important that teachers are sufficiently trained in the use of $\mathrm{BC}$ as this will have a direct impact on communication and student learning in the sessions (Wdowik, 2014). Additionally, teachers are required to demonstrate quick decision making under pressure, particularly with regards to technical difficulties (Bower et al., 2014) or multitasking in attending to students' reactions to feedback and chat history while delivering lesson content in PowerPoint (Nelson, 2017). The need for lecturers to 
establish classroom rules for BC sessions was also identified as crucial to the success of synchronous delivery (Yamagata-Lynch, 2014) alongside the establishment of a system of turn-taking with microphones (Bower et al., 2014). For example, in Tonsmann's (2014) exploration of the use of $\mathrm{BC}$ for a synchronous delivery of a discrete mathematics course in the U.S., the author opted to conduct sessions without a video-feed because most students did not utilise their cameras beyond the first few sessions.

While technical and instructional aspects such as the above are worth noting, $\mathrm{BC}$ is overall perceived by lecturers as a real-time virtual classroom that 'mimics an F2F classroom format in terms of students' performance outcomes' though the difference in the level of student engagement between face-to-face and BC sessions is still inconclusive (Francescucci \& Rohani, 2019, p . 67). This indicates the socioaffective complexity in delivering effective and engaging $\mathrm{BC}$ sessions that go beyond focusing solely on the content and technology in distance learning. Rather, it also hinges upon how lecturers build a virtual community supported by BC that further reinforces students' online learning experience and retainment of participation (Kilpatrick, 2019).

\section{Research Methods}

\section{Mixed Methods Design}

The study used a mixed methods design in the understanding that 'the use of both quantitative and qualitative methods, in combination, provides a better understanding of the research problem and question than either method by itself' (Creswell, 2012, p. 535) and that this approach is a 'legitimate inquiry approach' (Brewer \& Hunter, 1989, p. 28). In this instance, the qualitative data carried greater weight than the quantitative data. Only the first section of the survey instrument comprised closed-ended questions while the second section contained open-ended questions similar to those in the one-on-one, semi-structured interviews. The rationale for collecting both kinds of data even with such a small sample 
(seven respondents) was that the quantitative data could be collected at the same time as the qualitative data and used to triangulate and verify the qualitative data from the same participants (Creswell, 2012).

Moreover, the two strands of data could be 'merged', integrated, 'linked' and embedded to address the aims of the study (Creswell, 2012, p. 535) which were to investigate:

- lecturers' evaluations of the usefulness of Blackboard Collaborate for delivering online OUA units;

- the challenges for lecturers of incorporating Blackboard Collaborate as a virtual classroom into online OUA units;

- lecturers' perceptions of the impact of Blackboard Collaborate on distance learning and teaching via OUA.

\section{Setting and Participants}

Currently, many of the courses offered in the institution in this study are delivered online through the OUA. For example, the School of Education, in conjunction with the OUA, enrolls about 1500 first year students a year in the Early Childhood and Primary Language and Literacy unit of the Bachelor of Education alone. OUA lecturers familiar with Blackboard Collaborate within the Faculty of Humanities were contacted via email through unit coordinators, given information about the project and invited to participate. Those lecturers who gave consent to participate were then asked to complete an online survey and follow-up interview. The final sample consisted of seven tutor participants, three from the School of Education and four from the School of Built Environment. School of Education lecturers were teaching a language and literacy for educators unit and School of Built Environment lecturers were teaching building management, architecture or interior architecture units. All lecturers (two males and five females) utilised BC (see Figure 1) to 
conduct virtual classroom sessions in real time for their units as well as asynchronous tools such as Discussion Board and Blackboard Announcements.

(Insert Figure 1 here)

\section{Data Collection}

Quantitative data was collected via an online survey consisting of background items and close-ended statements about lecturers' perceptions of BC. Participants were asked to rate their agreement with the statements on a 5-point Likert scale. Internal consistency of the survey items was measured and an acceptable level of Cronbach's alpha at .63 was achieved, given the nature of this exploratory research (Hair, Black, Babin, Anderson, \& Tatham, 2006). The list of closed-ended statements is shown in Table 2 in the Findings.

Qualitative data was gathered via six open-ended questions included in the survey asking lecturers about their experiences with BC. These questions further probed lecturers' perceptions of the benefits and drawbacks of BC, the delivery of an online unit with or without $\mathrm{BC}$ and views on student engagement when $\mathrm{BC}$ is used. Lecturers who completed the survey were contacted and invited to arrange a convenient time for a one-on-one, semistructured interview conducted by one of the researchers. Since all the lecturers were already familiar with BC features, interview sessions were recorded in real time via the automatic record function in $\mathrm{BC}$ for the sake of face validity and subsequent analysis. Ethics clearance for data collection was obtained before approaching potential participants. Prior to the interview, participating lecturers were provided with an information sheet detailing the project aims and were asked to give signed consent to participate. Interview questions are listed in Table 1:

(insert Table 1 here)

\section{Data Analysis}


Thematic analysis was conducted to analyse the qualitative data to allow for 'holistic' responses, various interpretations of the participants' perspectives and more in-depth exploration of insiders' understandings of the investigated phenomenon (Miles, Huberman, \& Saldana, 2014). Each researcher recursively read through the interview transcripts and openended survey responses to gain a general feel about the data and conducted individual coding by identifying the salient patterns occurring repeatedly throughout the data. Afterwards, all researchers met to exchange their initial coding, discuss similar coded patterns, resolve differences in coding interpretations and reach the consensus of underlying conceptual themes at a higher level (Merriam, 2009). Participants' responses to the close-ended survey items, which focus on their experiences and perceptions of Blackboard Collaborate, were measured through descriptive statistical procedures. A full version of closed-ended survey statements is presented in Table 1 .

\section{Findings}

\section{Quantitative Data}

(Insert Table 2 here)

Overall, lecturers perceived the integration of BC in online teaching as an 'enjoyable' experience ( $100 \%$ agreement; $\mathrm{M}=4.71, \mathrm{SD}=.49)$. One of the factors that could have contributed to this is the 'user-friendliness' of BC's built-in features for videoconferencing $(\mathrm{M}=4.14, \mathrm{SD}=.69)$. They also expressed a preference for using this synchronous platform to support online students in OUA units rather than relying upon just the Discussion Board $(\mathrm{M}=4.29, \mathrm{SD}=.76)$. They felt that it facilitated a positive online teaching experience $(\mathrm{M}=4.29$, $\mathrm{SD}=.76$ ) and were not in favour of delivering an online unit fully offline (asynchronous) $(\mathrm{M}=2.43, \mathrm{SD}=1.40)$ or in agreement that teaching an online unit offline is time-saving $(\mathrm{M}=3.00, \mathrm{SD}=1.00)$. 
Lecturers' observations of the level of online students' sense of engagement and virtual community building via $\mathrm{BC}$ appeared to be positive with $80 \%$ agreement $(\mathrm{M}=4.29$, $\mathrm{SD}=.76$ and $\mathrm{M}=4.00, \mathrm{SD}=1.00$, respectively). They also felt that a virtual classroom could facilitate students' understanding of the content materials as lecturers could walk students through the lectures and address their queries in real time. This was better than students having to digest information with delayed replies from lecturers as in asynchronous mode $(\mathrm{M}=3.57, \mathrm{SD}=1.40)$. However, online lecturers also voiced their views on the negative aspects of using BC. Even though they did not feel intimidated by conducting BC sessions $(\mathrm{M}=1.71, \mathrm{SD}=.76)$, they nevertheless found that a virtual $\mathrm{BC}$ class did not entirely mirror its face-to-face counterpart $(M=2.71, S D=1.11)$. Lecturers expressed their liking for using a built-in camera and microphone to show their face $(\mathrm{M}=3.57, \mathrm{SD}=1.62)$ when talking to students in $\mathrm{BC}$ sessions $(\mathrm{M}=4.00, \mathrm{SD}=1.00)$. This was contrasted with less enthusiasm for using the text chat option ( $40 \%$ agreement; $\mathrm{M}=3.57 ; \mathrm{SD}=.98$ ). Lecturers were also less in agreement about the value of the interactive whiteboard $(\mathrm{M}=3.43, \mathrm{SD}=1.13)$ to communicate with students. This could mean that online lecturers still hope to conduct a virtual BC class as if they were seeing/talking to students in a face-to-face class. Hence, the creation of a sense of personalised, synchronous learning enhanced by tele/co-presence in fully online units seems to be very important for lecturers.

\section{Qualitative Data}

Three main areas of pre-occupation emerged from the lecturers' open-ended qualitative survey and interview questions: 1) learning and teaching, 2) virtual community building, and 3) expediency of the technology. Comments which pertained to learning and teaching fell into the categories of:

- engagement and motivation

- knowledge sharing 
- feedback

- multimodality

- approaches to teaching

In the area of engagement and motivation, one lecturer said she was 'passionate' about 'the whole system' of BC. Other lecturers claimed that students were more engaged by the use of this technology than face-to-face mode and this, therefore, led to higher marks for those students. On the downside, students could easily opt out from participating and there were those students who never bothered to log on. Knowledge could be easily shared with complex topics explained and illustrated with the addition of extra materials. However, this was sometimes hindered by the lack of procedures in place for formal turn-taking with students talking 'all at once' and then 'running ahead'. In short, an etiquette for interaction on $\mathrm{BC}$ was often missing. The advantage of $\mathrm{BC}$ as a tool for giving close, personal, 'one-on-one' feedback was identified by some participants, as was its conduciveness to multimodal teaching especially in the visual arts.

In terms of the effect lecturers perceived $\mathrm{BC}$ to have on their approaches to teaching, responses were mixed. One participant, in particular, felt that BC had impacted her teaching very positively. She said, 'I think my demeanour has become more professional ...I've had higher expectations of their [students] behaviour'. On a less positive note, lecturers complained that there was a 'distinct difference' between the virtual $\mathrm{BC}$ community and the classroom community in that the classroom allowed for 'constant interaction' where lecturers were able to give students things to find out, make deliberate mistakes and then ask the students: 'what's wrong here?' This is much more difficult to do using BC so a tutor has to modify his or her teaching style. Some lecturers also felt they needed to rehearse their performance a lot more as being recorded was more like 'show time'. 
As with the closed-ended responses, lecturers placed great importance on being able to see students' faces and felt that the live classroom facilitated this but BC often did not. Lecturers said they were 'unable to read their [students'] body language' and that their own use of gesture and the capacity to 'act out' was limited when using BC due to the limited panoramic capacity of the camera.

Lecturers also felt that $\mathrm{BC}$ could be an important tool in helping to build virtual learning and teaching communities which promoted networking and the making of friends and connections. It sometimes helped online lecturers to get to know individual students, especially when BC chat groups were small, and it could add a 'further dimension when trying to build a relationship with the students'. That relationship could lead to a greater sense of accountability on the part of the tutor. One tutor felt that students like to see that there is a person at the other end of the $\mathrm{BC}$ microphone. She went on to describe how she 'might have dirty dishes in the background' while she was delivering the session in order to break down barriers between students and lecturers. Students also had greater opportunities to engage with other online students through BC.

The drawbacks of using BC when trying to build a learning and teaching virtual community were that only small numbers of students attended the $\mathrm{BC}$ sessions. As one participant divulged, 'of the last three semesters, there's only ever been one or two students come on in real time... I ask them... there's been silence.' Some students 'hang back', according to another participant, and just rely on the text chat 'they're not really engaged ... [they are] like those students on campus who show up without any work to present.'

The expediency of the technology itself was also discussed in some detail by participants. The advantages of using an online platform such as BC were that lecturers were able to have the chance to rehearse their lectures beforehand and to create interesting slides for PowerPoint presentations using the five different windows available in BC. Some also felt 
that the $\mathrm{BC}$ sessions used time more efficiently than the face-to-face mode because lecturers were aware that lecture sessions were being recorded and therefore they got to the point more quickly. Moreover, the BC technology recreated a 'face-to-face feeling'.

Difficulties with the technology far outweighed the celebrations of the technology, however, with lecturers describing endless situations where the technology had either let them down or they had not been across it. Wait time was described as an impediment to student/tutor turn-taking and many felt interactive activities and tasks were limited by the BC medium. Moreover, workload was expanded by the time taken to prepare materials suitable for the BC medium and to perfect and rehearse lectures. Scheduling BC times convenient for all students and lecturers was also problematic.

\section{Discussion}

On the whole, lecturers in the study valued $\mathrm{BC}$ as a tool for being multimodal and knowledge sharing (Cornelius, 2014). They also felt that it could be an important platform for motivating and engaging students and building a close virtual community (Kilpatrick, 2019) with the capacity to give more rapid fire feedback in real time (Alexander et al., 2014; Hrastinski, 2008; Huang \& Hsiao, 2012; Peacock et al., 2012; Tunceren et al., 2015). However, this was offset by concerns about the way BC impacts their teaching approach, student engagement, problems with limited numbers of attendees online and dealing with technical problems (Akarasriworn \& Ku, 2013; Michael, 2012; Peacock et al., 2012).

The issue of student engagement can be merely a matter of scheduling but in many cases engagement also relies upon effective classroom management and teaching approaches, including the teacher's ability to 'read' the students (Lonie \& Andrews, 2009). One of the most pressing concerns that was raised in the study by lecturers, and one which will be focused on to some extent in this discussion, was their ability to create a cohesive virtual classroom when they often cannot see their students' faces (Kear et al., 2012). Lecturers 
shared the fact that they thought a sense of tele/co-presence enabled by configured cameras/microphones is paramount (Schroeder, 2002) and that they sometimes felt like they were talking to a void when students did not turn on their built-in cameras/microphones (Rogers, 2011). The tele/co-presence available to face-to-face lecturers is not available to lecturers in online asynchronous delivery as there is a shortage of discernible nonverbal (paralinguistic) cues available in modes such as BC. Several studies have documented this phenomenon. Cornelius (2014) interviewed lecturers about a web-conferencing experience with another online platform and concluded that, 'it is difficult to tell if learners understand what is being said or done in the absence of the visual clues used intuitively in a face-to-face context' (Cornelius, 2014, p. 286). In an effort to bridge the 'paralinguistic gap', one of the lecturers in the above mentioned study frequently used webcams and found that these enabled 'emotional responses to become part of the experience, providing additional opportunities for social bonding' (Cornelius, 2014, p. 268). However, the same lecturer also found that body language, particularly eye contact and interpretation of these cues differed as users do not often make direct eye contact with the camera.

Emotions and gestures can, of course, be displayed online by emoticons, ticks and crosses, etc and studies have shown that these can be appreciated by lecturers and students when they are routinely used in place of body language but they are often regarded as restricted and as having potential to be misinterpreted (Cornelius, 2014). Wang and Hsu (2008) reported difficulty with providing feedback online when the instructor is unable to use body language. Moreover, it is challenging to teach to all students' needs online as it is more difficult to identify students who are struggling during web conferencing because of the lack of feedback from students' facial expressions and body language (Kear et al, 2012; Lonie \& Andrews, 2009). 
One final point about the capturing of paralinguistics in online delivery of units is that in some courses it is absolutely essential that lecturers are able to demonstrate concepts physically. For example, Peacock et al. (2012) when talking about the use of the Wimba classroom for online Performing Arts students at one Scottish university, pointed out that information normally supported by non-verbal communication or physical correction such as instructing students on how an arm needs to move is difficult in an online mode using only a webcam. Data collected in this study also supported these findings.

A major concern of lecturers about using $\mathrm{BC}$ or any other technological tool was the fear and uncertainty that was created when the technology did not work. This response has been documented in other studies such as the one by Lavine et al. (2012). It goes without saying that student engagement will be greater in online forums when technical difficulties can be minimised. Whilst it is somewhat unrealistic to expect lecturers to have the technical expertise to be able to provide a smooth technological experience for students in every session (Wdowik, 2014), it is not unrealistic to expect full time technological assistance to be provided in tertiary institutions reliant upon online student cohorts.

\section{Implications and Conclusions}

As much as lecturers generally perceived $\mathrm{BC}$ as a facilitative platform for delivering online units, they also had some reservations about its use as an online learning and teaching tool. The big question that needs to be asked is whether this tool streamlines and adds value to learning and teaching or whether it detracts from this in some areas. It would seem that it is capable of both. The issues with technological expediency will no doubt be ironed out as the software becomes more sophisticated or as more institutions accept that full time technological assistance is essential in settings reliant upon online unit delivery via OUA. Nevertheless, issues connected with engagement are really down to the lecturer and the amount of thought that goes into the planning of the sessions, the teaching style adopted and 
the preparedness of the lecturer to provide multiple availabilities for students in all time zones and working arrangements. What may not receive the attention it needs in all of this is the consideration of paralinguistic communication by both lecturers and students and the importance of this for successful virtual classroom interaction. Innovation in the technology which can support this is the most pressing issue for online learning and teaching in distance education according to the participants in this study.

It is also acknowledged that the small sample size of this study does not allow for generalisable findings but both quantitative and qualitative findings corroborated each other and provided triangulation and trustworthiness to the data (Creswell, 2012). They reflect the context-specific phenomenon (i.e., OUA units) and insights from those lecturers offer lessons learned and best practices for likeminded lecturers or program directors who consider improving current OUA units or offering them in the future. Specifically, this study supports the positive results found in prior research that real-time virtual classrooms can make a difference in online students' learning experience, such as timely knowledge exchange and feedback provision as well as virtual community building via interactive multimodality. The findings also highlight the primacy of online student engagement, which is impacted by socioaffective factors in distance learning. These factors include the limitation of making nonverbal cues available to all the members in the BC session, and students opting not to show their tele-/copresence enabled by audio/video features. As such, these socioaffective challenges transcend the technological concerns and deserve more research and pedagogical attention in distance education.

\section{References}

Akarasriworn, C., \& Ku, H.-Y. (2013). Graduate students' knowledge construction and attitudes toward online synchronous videoconferencing collaborative learning environments. Quarterly Review of Distance Education, 14(1), 35-48. 
Alexander, M. M., Lynch, J. E., Rabinovich, T., \& Knutel, P. G. (2014). Snapshot of a hybrid learning environment. Quarterly Review of Distance Education, 15(1), 9-21.

Allen, I. E., \& Seaman, J. (2010). Learning on demand: Online education in the United States, 2009. Needham, MA: Sloan-C.

Blackboard to acquire Elluminate. (2010, July). CISION PR Newswire. Retrieved from https://www.prnewswire.com/news-releases/blackboard-to-acquire-elluminate-andwimba-97969544.html

Blackboard (2019). Blackboard Collaborate: Feature showcase. Retrieved from https://www.blackboard.com/online-collaborative-learning/blackboard-collaboratefeatures.html

Bower, M., Kenney, J., Dalgarno, B., Lee, M. J. W., \& Kennedy, G. E. (2014). Patterns and principles for blended synchronous learning: Engaging remote and face-to-face learners in rich-media real-time collaborative activities. Australasian Journal of Educational Technology, 30(3), 261-272. doi: 10.14742/ajet.v30i3.1697

Brewer, J., \& Hunter, A. (1989). Multimethod research: A synthesis of styles. Newbury Park, CA: Sage.

Carrington, D., Kim, S.-K., \& Strooper, P. (2010, January). An experience report on using collaboration technologies for distance and on-campus learning. In T. Clear \& J. Hamer (Eds.), ACE2010: Proceedings of the Twelfth Australasian Conference on Computing Education - Volume 103 (pp. 45-51). Darlinghurst, Australia: Australian Computer Society.

Cornelius, S. (2014). Facilitating in a demanding environment: Experiences of teaching in virtual classrooms using web conferencing. British Journal of Educational Technology, 45(2), 260-271. doi: 10.1111/bjet.12016 
Creswell, J.W. (2012). Educational research: planning, conducting, and evaluating quantitative and qualitative research (4th ed.). Upper Saddle River, NJ: Merrill Prentice Hall.

Ekwunife-Orakwue, K., \& Teng, T. (2014). The impact of transactional distance dialogic interactions on student learning outcomes in online and blended environments. Computers \& Education 78, 414-427. doi: 10.1016/j.compedu.2014.06.011

Francescucci, A., \& Rohani, L. (2019). Exclusively synchronous online (VIRI) learning: The impact on student performance and engagement outcomes. Journal of Marketing Education, 41(1), 60-69.

Hair, J., Black, W., Babin, B., Anderson, R., \& Tatham, R. (2006). Multivariate data analysis (6th ed.). Upper Saddle River, NJ: Pearson Prentice Hall.

Hrastinski, S. (2008). A study of asynchronous and synchronous online methods discovered that each supports different purposes. Educause Quarterly, 31(4), 51-55.

Huang, X. S., \& Hsiao, E. L. (2012). Synchronous and asynchronous communication in an online environment: Faculty experiences and perceptions. Quarterly Review of Distance Education, 13(1), 15-30,49-50. doi: 10.Ill 1/j.1083-6101.1999.tb00098.x

Irvine, V., Code, J., \& Richards, L. (2013). Realigning higher education for the 21 st century learner through multi-access learning. Journal of Online Learning and Teaching, 9(2), 172-186.

Kear, K., Chetwynd, F., Williams, J., \& Donelan, H. (2012). Web conferencing for synchronous online tutorials: Perspectives of tutors using a new medium. Computers \& Education, 58(3), 953-963. doi:10.1016/j.compedu.2011.10.015

Keengwe, J., \& Kidd, T. T. (2010). Towards best practices in online learning and teaching in higher education. MERLOT Journal of Online Learning and Teaching, 6(2), 533-541. 
Kilpatrick, C. D. (2019). Faces or fingers: Building community with synchronous chat. In J. Yoon \& P. Semingson (Eds.), Educational technology and resources for synchronous learning in higher education (pp. 1-22). Hershey, PA: IGI Global.

King, B. (2010). Reshaping distance and online education around a national university in regional Australia. Open Learning: The Journal of Open, Distance and e-Learning, 25(2), 131-140. doi: 10.1080/02680511003787404

Lavine, R., Greenburg, J., Chen, J., Kao, K., \& Lin, Y. (2012). East meets west: A virtual international teacher education initiative between the US and Taiwan. Journal of the International Society for Teacher Education, 16(1), 35-45.

Lonie, A.-L., \& Andrews, T. (2009). Creating a rich learning environment for remote postgraduate learners [online]. Education in Rural Australia, 19(1), 3-13.

Martin, F., Parker, M. A., \& Deale, D. F. (2012). Examining interactivity in synchronous virtual classrooms. The International Review of Research in Open and Distance Learning, 13(3), 227-261. doi: 10.19173/irrodl.v13i3.1174

Merriam, S. B. (2009). Qualitative research: A guide to design and implementation (3 ${ }^{\text {rd }}$ ed.). San Francisco: Jossey-Bass.

Michael, K. (2012). Virtual classroom: reflections of online learning. Campus-Wide Information Systems, 29(3), 156-165. doi: 10.1108/10650741211243175

Miles, M.B., Huberman, A.M., \& Saldana, J. (2014). Qualitative data analysis: a methods sourcebook. Thousand Oaks, CA: Sage Publications.

Nelson, L. (2017). Harnessing the power of the synchronous classroom in staff development. The Journal of Continuing Education in Nursing, 48(2), 62-64. doi:http://dx.doi.org/10.3928/00220124-20170119-05

Open Universities Australia (OUA) (2019). OUA pathways. Retrieved from https://www.open.edu.au/courses/preparatory/oua-pathways/ 
Peacock, S., Murray, S., Dean, J., Brown, D., Girdler, S., \& Mastrominico, B. (2012).

Exploring tutor and student experiences in online synchronous learning environments in the performing arts. Creative Education, 3(7), 1269-1280. doi: 10.4236/ce.2012.37186

Reese, S. A. (2014). Online learning environments in higher education: Connectivism vs. dissociation. Education and Information Technologies, 20(3), 579-588. doi: 10.1007/s10639-013-9303-7

Reushle, S., \& Loch, B. (2008). Conducting a trial of web conferencing software: Why, how and perceptions from the coalface. Turkish Online Journal of Distance Education, 9(3), $19-28$.

Rogers, C. (2011). Engaging students in online classes with WIMBA: A preliminary study. Paper presented at the Proceedings of the Southern Association for Information Systems Conference, Atlanta, GA.

Rudd, D. P., II, \& Rudd, D. P. (2014). The value of video in online instruction. Journal of Instructional Pedagogies, 13, 1-7.

Schroeder, R. (2002). Social interaction in virtual environments: key issues, common themes, and a framework for research. In R. Schroeder (Ed.), The social life of avatars: presence and interaction in shared virtual environments (pp. 1 - 16). London: Springer. doi: 10.1007/978-1-4471-0277-9_1

Tonsmann, G. (2014). A study of the effectiveness of Blackboard Collaborate for conducting synchronous courses at multiple locations. Insight: A Journal of the Centre for Excellence in Teaching and Learning, 9, 54-63.

Tunceren, L., Kaur, A., Mullins, C., \& Slimp, M. (2015). Technology review: personalizing the online enterprise of college learning through synchronous activity. The Community College Enterprise, 21(2), 103-106.

Wang, S. K., \& Hsu, H. Y. (2008). Use of the webinar tool (Elluminate) to support training: 
The effects of webinar-learning implementation from student-trainers' perspective. Journal of Interactive Online Learning, 7(3), 175-194.

Wdowik, S. (2014). Using a synchronous online learning environment to promote and enhance transactional engagement beyond the classroom. Campus - Wide Information Systems, 31(4), 264-275. doi: 10.1108/CWIS-10-2013-0057

Yamagata-Lynch, L. C. (2014). Blending online asynchronous and synchronous learning. International Review of Research in Open and Distance Learning, 15(2), 189-212. doi: 10.19173/irrodl.v15i2.1778 
Table 1

Semi-structured Interview Protocol

\section{Items Questions}

\begin{tabular}{cl}
\hline 1 & What differences in student engagement do you notice in units which make use \\
& of Blackboard Collaborate? \\
\hline 2 & How do you feel about presenting content during Blackboard Collaborate \\
& sessions compared with face-to-face contact? Have you observed any changes in \\
& your behaviour? \\
\hline 3 & If the answer was 'yes', can you describe the differences? \\
\hline 5 & Are there any drawbacks or challenges of using Blackboard Collaborate? \\
\hline 6 & What features of Blackboard Collaborate have you used or would you like to use \\
& to further enhance the student online learning experience? \\
\hline & online units?
\end{tabular}


Table 2

Lecturers' Responses to the Closed-ended Survey Questions

Closed-ended Survey Items

(5 Strongly Agree 1: Strongly Disagree)

I think using $\mathrm{BC}$ enhances my online teaching

experience.

I find BC user-friendly.

4.14

.69

(SD)

Mean (M) Std. Deviation Agree*S.A.

I feel that students are more engaged when BC

4.29

.76

$80.0 \%$

is used in an online unit.

\begin{tabular}{llll}
\hline I feel that students feel a sense of belonging to & 4.00 & 1.00 & $80.0 \%$
\end{tabular} the online class in a BC session.

I prefer having $\mathrm{BC}$ in an online unit than a

4.29

.76

$100 \%$

totally offline unit.

When I am in a BC session, I feel more

1.71

.76

$0.0 \%$

nervous lecturing than in a face-to-face class.

\begin{tabular}{llll}
\hline I like to use the microphone to speak in a BC & 4.00 & 1.00 & $60.0 \%$
\end{tabular}
session.

\begin{tabular}{llll}
\hline I like to use text chat to communicate with the & 3.57 & .98 & $40 \%$
\end{tabular} students in a $\mathrm{BC}$ session.

$\begin{array}{llll}\text { I like to show my face via video in a BC } & 3.57 & 1.62 & 60 \%\end{array}$ session.

\begin{tabular}{lccc}
\hline I like to see my students' faces in a BC session. & 4.29 & .95 & $60 \%$ \\
\hline I think the interactive whiteboard in BC is & 3.43 & 1.13 & $40 \%$ \\
helpful. & & &
\end{tabular}

\begin{tabular}{llll}
\hline I feel a virtual BC session is similar to a face- & 2.71 & 1.11 & $40 \%$
\end{tabular} 
to-face class.

$\begin{array}{llll}\text { I think students can understand material better } & 3.57 & 1.40 & 80 \%\end{array}$ in a $\mathrm{BC}$ session than an offline mode.

\begin{tabular}{llll}
\hline I prefer an online unit that is delivered in an & 2.43 & 1.40 & $0.0 \%$
\end{tabular} offline (asynchronous) mode because it is easier.

\begin{tabular}{llll}
\hline I think an online unit that is delivered in an & 3.00 & 1.00 & $0.0 \%$
\end{tabular} offline (asynchronous) mode saves time.

$\begin{array}{llll}\text { Overall, I enjoy teaching an online unit when } & 4.71 & .49 & 100 \%\end{array}$ $\mathrm{BC}$ is included.

Notes:

1. $\mathrm{N}=7$

2. Cronbach's $\alpha=.63$

3. Agree*S.A. = 'Agree' and 'Strongly Agree' percentage combined 